\title{
Interactive comment on "Estimation of pollen counts from light scattering intensity when sampling multiple pollen taxa - Establishment of Automated Multi-taxa Pollen Counting Estimation System (AME System)" by Kenji Miki and Shigeto Kawashima
}

Kenji Miki and Shigeto Kawashima

kmiki@elsi.jp

Received and published: 26 October 2020

To reviewer 2,

Thank you very much for your very constructive advice and suggestions. I made some correction following your comments. 
(Fig.1) to show the experimental setup.

Q2 It is more general to call "forward" scattering than "front" scattering. A2 I changed all "front" into "forward" in the draft.

Q3 It is helpful if authors can provide the approximate particles diameter range corresponding to the measured range of light scattering signals whose unit is volt.

Interactive

comment

A3 I totally agree that it will be very helpful if we would be able to provide the relationship between particle size and light scattering signals and it has been indeed a very important discussion point for the realisation of automated pollen counting system. However, the relationship between the strength of the signal in voltage is determined by multiple physical properties (size, roughness, etc.) of sampled particle as discussed in Matsuda and Kawashima (2018), so it might be misleading to generalise the relationship between the particle diameter and signal strength. I added some sentences explaining this to add more clearness.

Q4 Page 4, Line 136-137 P_Alnus_front should be changed to P_Artemisia_side A4 I made the revision following the advice.

Q5 Probability density function shown in Figure 4 may be omitted as they have the same profile as the number of pollen incidents versus the voltage.

A5 I deleted the figures of the probability densities following your advice.

Thank you very much for your advice again.

Interactive comment on Atmos. Meas. Tech. Discuss., doi:10.5194/amt-2020-320, 2020. 


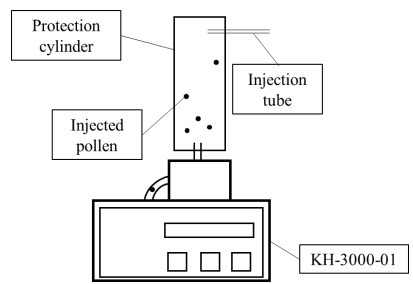

Interactive comment 